Sokoto Journal of Veterinary Sciences (ISSN 1595-093X)

Hena et al. /Sokoto Journal of Veterinary Sciences (2012). 10(1):13-16. http://dx.doi.org/10.4314/sokjvs.v10i1.3

\title{
Radiographic studies of developing calvaria at prenatal stages in one-humped camel
}

\author{
SA Hena ${ }^{1}$, ML Sonfada ${ }^{1}$, BI Onyeanusi ${ }^{2}$, ROC Kene $^{3} \&$ A Bello $^{1}$ \\ ${ }^{1}$ Department of Veterinary Anatomy, Faculty of Veterinary Medicine, Usmanu Danfodiyo University, Sokoto, Nigeria. \\ ${ }^{2}$ Department of Veterinary Anatomy, Faculty of Veterinary Medicine, Ahmadu Bello University Zaria, Nigeria. \\ ${ }^{3}$ Department of Surgery and Radiology, Faculty of Veterinary Medicine, Usmanu Danfodiyo University, Sokoto, Nigeria.
}

\section{Abstract}

Radiographic studies on the fetal heads of 32 one-humped camels (Camelus dromedarius) with 11 fetuses at the first trimester, 12 at the second trimester and 9 at the third trimester levels were conducted in Sokoto Metropolis. The study involved the radiographic evaluation of calvaria of different fetuses at first, second and third trimester stages of the gestational ages. Radiographic observations made in this study revealed that the onset of mineralization was recognizable even at the first trimester stage through the radio-opaque appearances of the calvaria appearing whiter on radiographs. This tendency however increased with increase in gestational age of the fetuses showing that because of their highly calcified calvaria, the fetuses at the third trimester were more radioopaque to X-ray energy thus appearing whiter on the radiographs. Sutural demarcations were not clear on the radiographs made in this study, but however, clear evidences of fontanels were seen as localised radio-lucent areas on the calvaria more especially at the first trimester stage. The findings in this research would help in understanding the radiographical anatomy of the developing calvaria in this animal species.
\end{abstract}

Keywords: Calvaria, Camel, prenatal, radiography.

\section{Introduction}

Camel is an important animal reared in both the desert and semi-desert tropics and what made the camel so special in the deserts and semi-deserts is its ability to survive the drought conditions by many and varied physiological mechanisms. The activities of the camel is being coordinated and controlled by the brain, and the brain being so delicate, needs to be protected by the calvarium.

The roof of the skull (cranial vault or skull cap) is the calvarium; it is formed by parietal and frontal bones, although caudally the interparietal process of the occipital bone contributes to its formation (Smuts \& Bezuidenhout, 1987). The rostral two-third of the base of cranium is formed by sphenoid bones and the caudal one-third by the basioccipital. The caudal wall is formed by the occipitals and the rostral wall by the cribriform plate of the ethmoid. The lateral wall on each side is formed by the temporal, parietal, and frontal bones, although ventrally the sphenoid and caudally the occipital bones contribute to its formation (Smuts \& Bezuidenhout, 1987; Evans, 1993), the interparietal bone is prominent and it is part of the calvarium at the fetal stage.

A radiographical study of the head is an important tool in the field of anatomy and for diagnostic purposes in both animal and human subject (Anonymous, 2011). Radiographic anatomy of the head region is quite difficult to understand due to complex arrangement of numerous structures (Dyce et al., 2010). Evaluation of traumatic diseases and mass changed deformities of the head make it necessary to have a good imagination of detailed normal structures of the head, thus there is the need to establish morphologic and radiographic data of the fetal calvarium of the camel. The result obtained in the present study will describe the radiographic appearances of the calvarium in order to ascertain the calcification of each camel fetal head at various stages of its development.

\section{Materials and methods}

Wasted camel fetuses were collected from the metropolitan abattoir through daily visit to Sokoto abattoir in Nigeria for a period of six months. The fetuses collected were examined and apparently appeared healthy, they were then cleaned and put into polythene bags and transported to the Veterinary Anatomy laboratory of Usmanu Danfodiyo University Sokoto, where they were 
weighed using a beam balance (Salter, No. 511, made in England) with a sensitivity of $0.001 \mathrm{~kg}$, and the crown-rump vertebral length measured and recorded in centimetres using a tape rule (Butterfly type $\left.{ }^{(\mathrm{R})}\right)$ with a sensitivity of $0.1 \mathrm{~cm}$. Fetuses were then categorized into definite trimesters according to El-Wishy et al., (1981). The fetuses were then decapitated at the occipito-atlantal joint as described by Vimini et al., (1983) and the samples were later transferred to the radiology unit of the Veterinary Teaching Hospital, Usmanu Danfodiyo University Sokoto for radiographic procedures.

Each fetal head was weighed and placed first on the exocranial surface, then on a lateral view on top of a radiographic film cassette over the radiographic table to obtain two views of exposure. Each sample was centrally placed on the X-ray table over the Xray film, sometimes supported with cotton wool to achieve good positioning. Each head was exposed to X-ray at a standard distance of $50 \mathrm{~cm}$ for 1.6 seconds at $60 \mathrm{KVA}$ and $20 \mathrm{MA}$ using the sovereign II portable X-ray machine (PLH Medical Ltd, Watford Herts, UK); the films were processed, viewed and

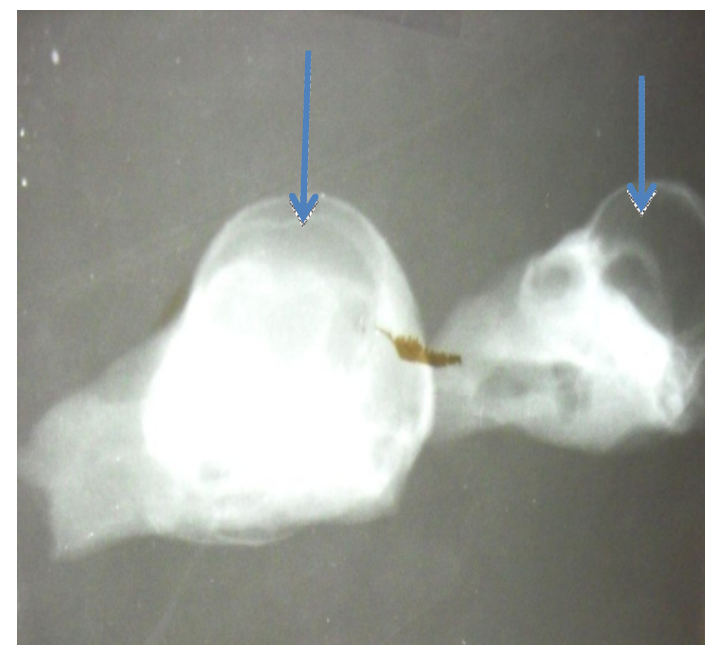

Plate I: Lateral view of first trimester fetal skulls showing radiolucent calvaria and anterior fontaneles (Blue arrows) [Magnification $\times 125$ ] studied using the X-ray viewer while photographs were taken using a digital camera (Samsung, ES10, 8.1 Mega pixels).

\section{Results}

The calvaria of the first trimester fetuses had clear fontaneles, appearing radiolucent on the radiographs (Plates I \& II), and the fontaneles tended to disappear with advancement in age at the second and third trimesters stages (Plates III \& IV). The radiographic findings revealed the prominence of the anterior fontanele which appeared translucent (dark) with a relative radio-opaque (white) surrounding at the level of first the trimester aged fetuses. There was slight radio-opacity of the calvaria in the first and second trimester fetuses relative to the third trimester fetuses at which stage radio-opacity became more widespread and progressively prominent. Fetal heads at third trimester had greater radiopacity which appeared much whiter on the radiographs (Plate IV).

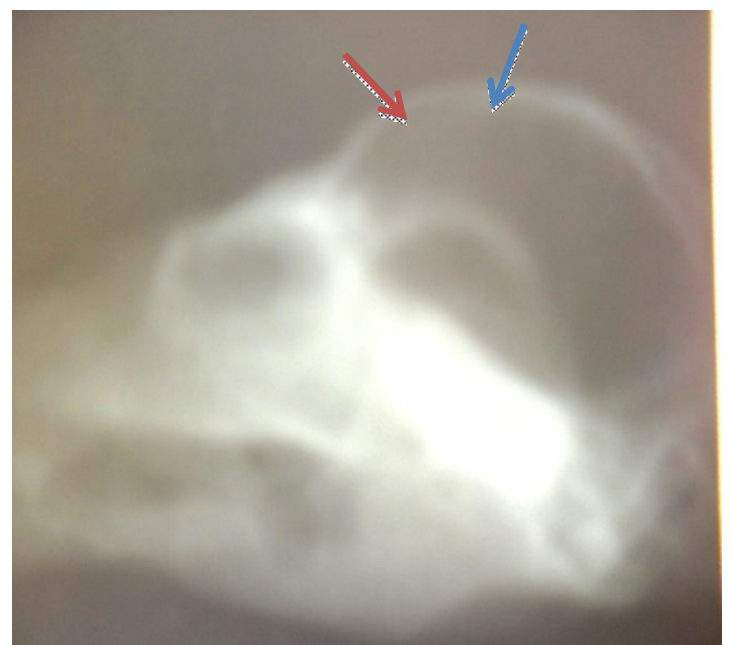

Plate II: Lateral view of first trimester fetal skull showing radiolucent calvarium (red arrow) and anterior fontanele (blue arrow) [Magnification $\times 125$ ] 


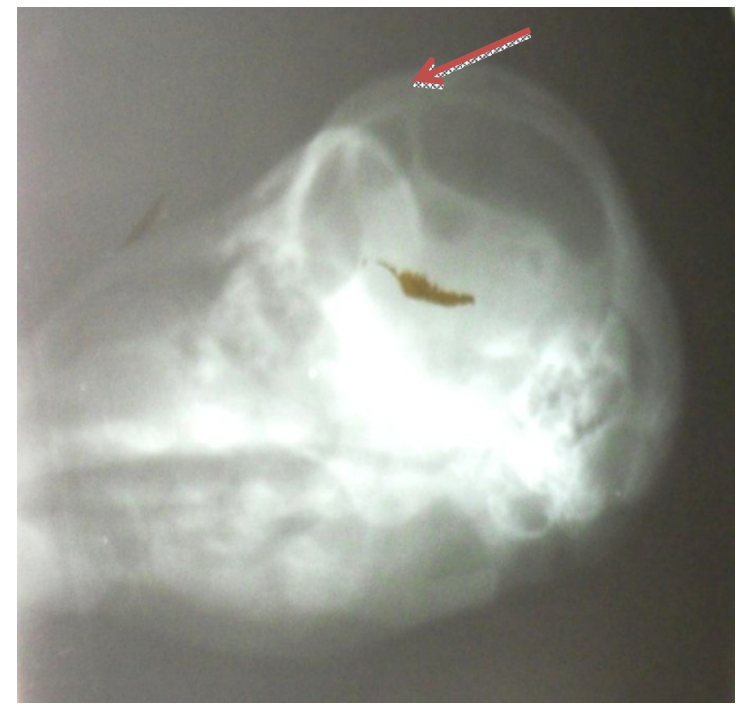

Plate III: Lateral view of second trimester fetal skull showing radiolucent calvarium (red arrow) [Magnification $\times 125$ ]

\section{Discussion}

Radiographic observations made in this study revealed that the onset of calcification was recognizable even at the first trimester through the radio-opaque appearance of the calvaria (which appeared whiter on radiographs). This appearance increased with increase in gestational age showing that fetuses at third trimesters were more radioopaque to X-ray energy because of their highly calcified calvaria. Bones are radio-opaque, thus they attenuate X-ray energy more than other tissues and appeared white on radiographs. An extensive radioopacity both in spread and depth was recognizable with advanced development, leading to the calvarium being calcified heavily at the third trimester of the fetal age; this finding was in agreement to the findings reported by Sivachelvan et al., (1995) in Sahel goat.

A radiographic picture of the head is a valuable aid for diagnostic purposes and for research concerning the growth of the head in humans and animals (Anonymous, 2011). In many instances, a radiograph of the head according to Shojaei et al., (2008), is used as a representation of the bony and soft tissues of the head; however, the soft tissues as well as the complex arrangements of numerous structures of the head may influence the measurements of the bony parts, thus making a radiographic anatomy of the head region difficult to understand. This

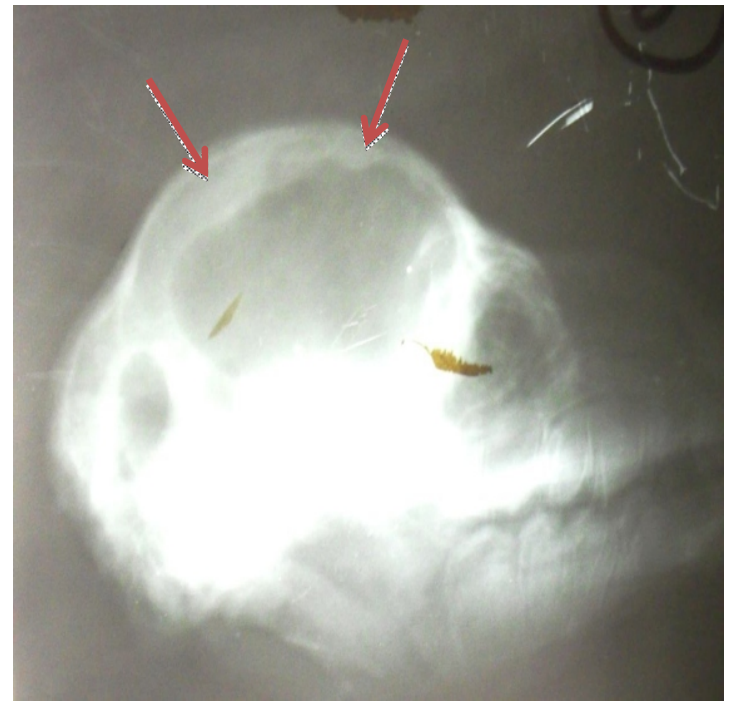

Plate IV: Lateral view of third trimester fetal skull showing a relative radio-opacity of the calvarium indicating heavy calcification (Red arrows) [Magnification $\times 125$ ]

phenomenom had been encountered in this research from the radiographs made on dorsoventral positions as they had some distorted effects as a result of soft tissue superimpositions.

In this study, inter-bony sutures were not clearly distinguishable radiographically but the anterior fontaneles were clearly seen at the radiographs of the first and second trimester fetuses. The radiolucency of this area may also support the concept of poor mineralization of the frontal and parietal bones in contrast to the other bones of the calvarium (Peterson \& Dechow 2002; Arntsen et al, 2008); this could then form a basis for the choice of such region in stunning during humane killing at postnatal stage. The observations made in this study will add to the few available literatures on the calvaria development of camel.

We wish to recommend the use of magnetic resonance imaging (MRI) studies on the fetal as well as adult camel calvaria for additional and deeper understanding of the development and form of the calvaria in this animal species.

\section{Acknowledgement}

We acknowledge the support and efforts of the departmental staff members of the Veterinary Anatomy, Faculty of Veterinary Medicine, Usmanu Danfodiyo University, Sokoto. 


\section{References}

Arntsen T, Kjaer I \& Sonnesen L (2008). Skull thickness in patients with skeletal class II and class III malocclusions. Orthopaedic and Craniofacial Researches, 11(4):229-34.

Dyce KM, Sack WO \& Wensing CGJ (2010). Text book of Veterinary Anatomy. (4 $4^{\text {th }}$ Edition). Saunder's Company, Philadelphia. Pp 16, 57-65.

El-wishy AB, Hemeida NA, Omar MA, Mobarak AM \& El-sayed MAI (1981). Functional changes in the pregnant camel with special reference to fetal growth. British Veterinary Journal, 137:527-537.

Evans HE (1993). Miller's Anatomy of the Dog (4th Edition). Saunder's Company. Pp 59-71.

Peterson J \& Dechow PC (2002). Material Properties of the Inner and Outer Cortical Tables of the Human Parietal Bone. The Anatomical Records, 268:7-15.
Shojaei B, Masoudifard M, Vajhi AR, Soroori S \& Faskhoodi D (2008). Lateral and Dorsoventral Radiographic Anatomy of the Head Bones of One-Humped Camel (Camelus dromedarius).In: Proceedings of the 15th Congress of FAVA 27-30 October. FAVA OIE Joint Symposium on Emerging Diseases Bangkok, Thailand. Pp 303-305.

Sivachelvan MN, Hajara BU \& Chibuzor GA (1995). Fetal development of the calvarium in Sahel goat: its post-natal significance. Tropical Veterinarian, 13 (3\&4):109-118.

Smuts MS \& Bezuidenhout AJ (1987). Anatomy of the Dromedary. Oxford University Press, Wanton Street, Oxford OX2 6DP. Pp 1-10.

Vimini RJ, Field RA, Riley ML \& Varnell TR (1983). Effect of delayed bleeding after captive bolt stunning on heart activity and blood removal in beef in beef cattle. Journal of Animal Science, 57:628-631. 